\title{
IMPLEMENTATION OF CORRELATION ANALYSIS TO WORK SAMPLING RESULTS
}

\author{
Borut Buchmeister \& Palcic Iztok
}
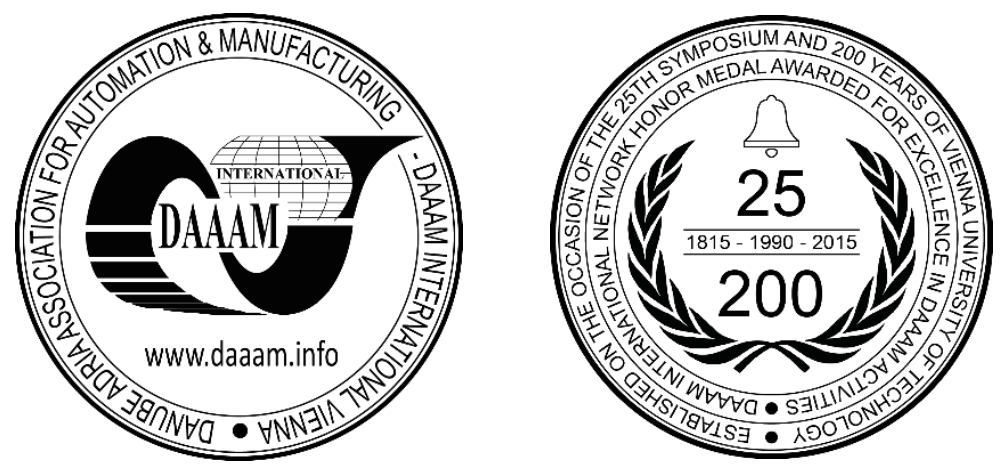

This Publication has to be referred as: Buchmeister, B[orut] \& Palcic, I[ztok] (2017). Implementation of Correlation Analysis to Work Sampling Results, Proceedings of the 28th DAAAM International Symposium, pp.0029-0034, B. Katalinic (Ed.), Published by DAAAM International, ISBN 978-3-902734-11-2, ISSN 1726-9679, Vienna, Austria DOI: $10.2507 / 28$ th.daaam.proceedings.004

\begin{abstract}
Work sampling is the process that estimates the proportion of time of the workday spent by workers (or machines) on different activities (work or non-work), based on sufficient random observations of activities over a period of time. When jobs do not have short cycle times or high repetition rates the use of such statistical technique is required, because work sampling data can provide information that can be used to establish standards. The work sampling procedure is well standardized by the recommended steps, but some contributions are possible in the evaluation of the observations.

In the paper we present our contribution in the improvement of the decision process based on the work sampling data. We introduce the correlation comparison of the measured hourly proportions of all pairs of activities to check, if there are some interrelationships. The results enable easier decision making (conclusions) about the influence of the selected activities to trigger the others. This is bringing us to better production system's efficiency and productivity.
\end{abstract}

Keywords: Work sampling; Activities; Observations; Correlation analysis; Decision making

\section{Introduction}

In many industries the presence of labour with high productivity at each stage plays a significant role in achieving success [1]. There are many jobs where time study, standard data, and predetermined time standards just are not useful, productive ways to set standards. When jobs do not have short cycle times or high repetition rates, such as those in maintenance, material handling, clerical and the like, these methods are not effective [2]. Jobs with long cycle times and low frequency of repetition require the use of work sampling [3, 4, 5].

Work sampling (introduced by L. H. C. Tippett in 1934 in the textile industry) is the process of making sufficient random observations of an operator's activities to determine the relative amount of time the operator spends on the various activities associated with the job. Work sampling method is used for collection of empirical data. Although it is not the express purpose of work sampling to determine how long specific tasks should take, work sampling data, when coupled with historical production data for key volume indicators and performance levelling, can provide information that can be used to establish standards [6, 7]. The major goal of work sampling, however, is to determine the proportion of the workday spent on certain types of work. To set the amount of time required to perform a task is not a goal of work $\underline{\text { sampling }[8,9,10] \text {. Work sampling can also give us an insight to activities structure and related physical exposures which }}$ 
may cause heavy injuries $[11,12]$. So it is useful for indirect assessment of workplace exposures and injury risk factors. With work sampling approach we can also record workers' satisfaction levels (when performing some tasks) to study how different tasks influence workers' satisfaction with their work [13].

Rather than observing the worker constantly for many days, the data collector may observe the workers at 15 to 30 instances during each day for two weeks or more. These observations are simply snapshots of what the workers are doing at that moment. If enough observations are made over a sufficiently long and representative period of time, the fraction of time workers spend on various activities can be estimated statistically. Work sampling estimates include some degree of error. The same number of observations taken at different times during the week will produce different estimates, and all estimates will usually differ from the actual (unknown) values.

The main advantages of work sampling are [14]:

- Observations are spread out over a period of time, making results less susceptible to short-term fluctuations.

- There is little or no disruption of work.

- Workers are less resentful.

- Studies are less costly and less time-consuming, and the skill requirements of the analyst are much less than at other methods.

- The study can be interrupted without affecting the results.

- Many different studies can be conducted simultaneously.

- No timing device is required.

And some disadvantages of work sampling [14]:

- There is much less detail on the elements of a job.

- Workers may alter their work patterns when they spot the observer, thereby invalidating the results.

- It is not well suited for short, repetitive tasks.

- Much time may be required to move from one workplace to another and back to satisfy the randomness requirement.

\section{Methodology}

The method to conduct a work sampling study is as follows [3, 15]:

- Establish the purpose of the study. Is the intent to set a standard to drive staffing levels or is it to identify the proportion of time spent on each major category of work?

- Identify the subjects. Who is doing the work within the organization? Careful problem definition can prevent mistakes such as studying the wrong worker or wrong activity.

- Identify the measures of output. This is essential if the objective of the study is to develop standards.

- Establish a time period for the study. The period of the study should be long enough to be representative of normal operations.

- Define the activities. This includes a definition of the major tasks performed. An example of some work definitions is included in a case study in section 4.

- Determine the number of observations needed. After the work elements are defined, the number of observations for the desired accuracy and confidence level must be determined.

- Schedule the observations. If an analyst will record the data, use a random number table or random number generator. Only randomly distributed observation times will reflect typical performance.

- Inform the personnel involved. As in any productivity measurement study this part of the procedure is important. Workers and their supervisors might think that they personally are being measured rather than the work they are doing.

- Record the raw data (manually written on the sheet of paper or by notepad, by portable computer, by special recording device etc.).

- Summarize the data. Determine the proportion of time spent on each activity.

Work sampling studies are easy and inexpensive to perform. One observer can monitor and sample the behaviour of several workers during the same period. To carry out data collection, each observer selects a number of workers performing the same operation. A work sampling study usually requires a substantial period of time to complete. The minimum number of observations $\left(N_{o b s}\right)$ necessary to achieve the desired level of accuracy and confidence can be computed by:

$$
N_{o b s}=\left(z^{2} \cdot \dot{p} \cdot(1-\dot{p})\right) / e^{2}
$$


where $\dot{p}$ is the proportion of observations during which the target activity is performed, $z$-value is a factor for the confidence level (typically $z=1.96$ for $95 \%$ confidence level), $e$ is the maximum absolute error desired (between 0.01 and 0.05).

As mentioned before the most important issue is what fraction of time is spent doing each type of activity, or what fraction of time is spent on productive work versus idle time or unproductive work [16]. Reports include: activities' proportion (for whole study), activities' proportion during a work day (for hours 1 to 8), activities' proportion related to days of a week (Monday to Friday), and activities' proportion related to work shifts (1 to 3 ).

\section{Inclusion of the correlation analysis}

Within the results we have also the proportions of all observed activities during workday hours (1 to 8$)$. We can presume that sometimes specific activities trigger the occurrence of another activity (or more activities). If such activities are unproductive, then we are able to prevent the appearance of selected activities (mainly in the field of idle time) with the goal to reduce losses, caused by such interrelationships.

So we compare the hourly proportions ( 8 data) of all pairs of activities using the equation for the correlation coefficient:

$$
r=\frac{8 \cdot \Sigma x y-(\Sigma x) \cdot(\Sigma y)}{\sqrt{\left(8 \cdot \Sigma x^{2}-(\Sigma x)^{2}\right) \cdot\left(8 \cdot \Sigma y^{2}-(\Sigma y)^{2}\right)}}
$$

where $r$ is the correlation coefficient, $x$ is the proportion of the first compared activity and $y$ the same for the second activity (both for 8 hours). The result is between -1 and 1, where: 1 indicates a strong positive relationship, -1 indicates a strong negative relationship, and a result of zero indicates no relationship at all. We suggest that all results lower than 0.6 and higher than 0.6 should be considered. This additional calculation in results' analysis is the main contribution of our paper.

\section{Case study}

In a textile company we have made the necessary observations in the frame of work sampling project. For the purpose of this paper the assembly workplaces' data (1600 observations) for 17 activities were used for the analysis. The activities and their proportions during the 8 -hours workday (with a 30 minutes break in the $4^{\text {th }}$ hour) are collected in Table 1.

\begin{tabular}{|l|c|c|c|c|c|c|c|c|}
\hline \multirow{2}{*}{ Activity } & \multicolumn{7}{|c|}{ Proportion of time in the hour of a workday [\%] } \\
\cline { 2 - 9 } & $\mathbf{1}$ & $\mathbf{2}$ & $\mathbf{3}$ & $\mathbf{4}$ & $\mathbf{5}$ & $\mathbf{6}$ & $\mathbf{7}$ & $\mathbf{8}$ \\
\hline 1. Complete all parts & 14.00 & 15.00 & 17.00 & 18.00 & 12.50 & 18.00 & 12.00 & 13.50 \\
\hline 2. Assembly the parts & 58.50 & 56.00 & 53.50 & 41.50 & 42.50 & 53.50 & 49.00 & 45.50 \\
\hline 3. Depositing the parts & 14.00 & 17.50 & 14.50 & 5.50 & 15.50 & 17.50 & 14.00 & 13.00 \\
\hline 4. Annotation of work results & 1.50 & 0.50 & 0.00 & 0.50 & 1.00 & 0.50 & 1.00 & 5.00 \\
\hline 5. Cleaning the machine & 0.00 & 0.00 & 0.00 & 0.00 & 0.00 & 0.00 & 0.00 & 1.50 \\
\hline 6. Keeping workplace in order & 0.00 & 0.00 & 0.00 & 0.00 & 0.00 & 0.00 & 0.00 & 8.50 \\
\hline 7. Conversation about tasks & 0.00 & 0.00 & 0.50 & 1.50 & 0.00 & 0.00 & 0.00 & 2.50 \\
\hline 8. Idle time (waiting for duties) & 2.50 & 2.00 & 1.00 & 1.00 & 1.00 & 0.00 & 0.50 & 0.50 \\
\hline 9. Waiting time - bad quality & 0.00 & 0.00 & 1.00 & 0.00 & 0.00 & 0.00 & 0.00 & 0.00 \\
\hline 10. Waiting time - missing device & 0.00 & 0.00 & 0.00 & 0.00 & 0.00 & 0.00 & 0.00 & 0.00 \\
\hline 11. Machine failure & 0.00 & 0.00 & 0.00 & 0.00 & 0.00 & 0.00 & 0.50 & 0.00 \\
\hline 12. Repair of defects & 0.00 & 0.00 & 0.50 & 0.00 & 0.00 & 0.50 & 0.00 & 0.00 \\
\hline 13. Business meeting & 0.00 & 0.00 & 0.00 & 1.50 & 2.50 & 0.00 & 0.00 & 0.00 \\
\hline 14. Work on other workplace & 0.00 & 0.00 & 0.50 & 1.50 & 0.00 & 0.00 & 0.00 & 0.00 \\
\hline 15. Absence from company & 4.00 & 4.00 & 6.00 & 6.00 & 6.00 & 5.00 & 4.50 & 6.00 \\
\hline 16. Private conversation & 2.00 & 0.50 & 0.50 & 0.50 & 0.00 & 1.00 & 3.50 & 2.00 \\
\hline 17. Private absence from workplace & 3.50 & 4.50 & 5.00 & 22.50 & 19.00 & 4.00 & 15.00 & 2.00 \\
\hline Total: Productive work & 86.50 & 88.50 & 85.00 & 65.00 & 70.50 & 89.00 & 75.00 & 72.00 \\
\hline Total: Losses & 13.50 & 11.50 & 15.00 & 35.00 & 29.50 & 11.00 & 25.00 & 28.00 \\
\hline
\end{tabular}

Table 1. Time usage within a workday (hourly report)

The results collected in Table 1 are partly presented in graphical form (see Fig. 1) showing proportions of time in the hours of a workday for individual activities. 

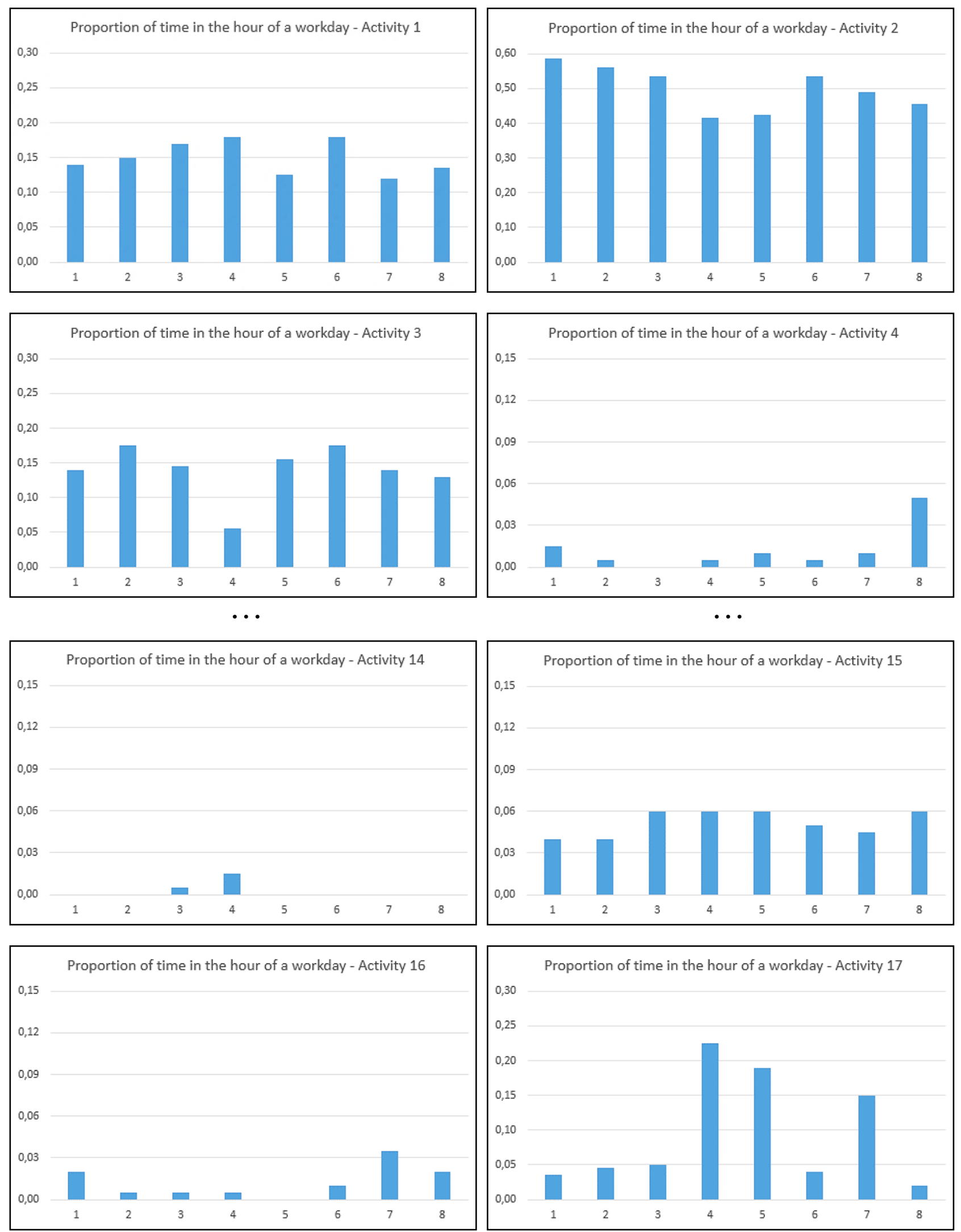

Fig. 1. Proportions of time in the hours of a workday for the selected activities 1, 2, 3, 4, 14, 15, 16 and 17

Similar course of productive work time proportions at specific activities may show us possible interrelationships between these activities.

The results of the pairwise correlation calculation using (2) are summarized in the Table 2. All values are multiplied by 10 and rounded (so, values between -9 and +9 appear). 


\begin{tabular}{|c|c|c|c|c|c|c|c|c|c|c|c|c|c|c|c|c|c|}
\hline Act. & $\mathbf{1}$ & $\mathbf{2}$ & $\mathbf{3}$ & $\mathbf{4}$ & $\mathbf{5}$ & $\mathbf{6}$ & $\mathbf{7}$ & $\mathbf{8}$ & $\mathbf{9}$ & $\mathbf{1 0}$ & $\mathbf{1 1}$ & $\mathbf{1 2}$ & $\mathbf{1 3}$ & $\mathbf{1 4}$ & $\mathbf{1 5}$ & $\mathbf{1 6}$ & $\mathbf{1 7}$ \\
\hline $\mathbf{1}$ & $/$ & 1 & -2 & -4 & -2 & -2 & 1 & -1 & 3 & 0 & -5 & 6 & -1 & 6 & 2 & -5 & 0 \\
\hline $\mathbf{2}$ & & $/$ & 5 & -2 & -2 & -2 & -5 & 4 & 2 & 0 & 0 & 3 & -7 & -4 & -7 & 1 & -7 \\
\hline $\mathbf{3}$ & & & $/$ & 0 & -1 & -1 & -5 & 0 & 0 & 0 & 0 & 3 & -3 & -8 & -4 & 0 & -5 \\
\hline $\mathbf{4}$ & & & & $/$ & 9 & 9 & 7 & -1 & -3 & 0 & 0 & -3 & -1 & -2 & 2 & 3 & -3 \\
\hline $\mathbf{5}$ & & & & & $/$ & 9 & 8 & -2 & -1 & 0 & -1 & -2 & -2 & -1 & 3 & 2 & -3 \\
\hline $\mathbf{6}$ & & & & & & $/$ & 8 & -2 & -1 & 0 & -1 & -2 & -2 & -1 & 3 & 2 & -3 \\
\hline $\mathbf{7}$ & & & & & & & $/$ & -2 & 0 & 0 & -2 & -2 & 0 & 3 & 6 & 0 & 0 \\
\hline $\mathbf{8}$ & & & & & & & & $/$ & 0 & 0 & -2 & -4 & 0 & 0 & -5 & -1 & -1 \\
\hline $\mathbf{9}$ & & & & & & & & & $/$ & 0 & -1 & 6 & -2 & 1 & 3 & -2 & -2 \\
\hline $\mathbf{1 0}$ & & & & & & & & & & $/$ & 0 & 0 & 0 & 0 & 0 & 0 & 0 \\
\hline $\mathbf{1 1}$ & & & & & & & & & & & $/$ & -2 & -2 & -1 & -3 & 7 & 2 \\
\hline $\mathbf{1 2}$ & & & & & & & & & & & & $/$ & -3 & 0 & 2 & -2 & -3 \\
\hline $\mathbf{1 3}$ & & & & & & & & & & & & & $/$ & 3 & 5 & -5 & 7 \\
\hline $\mathbf{1 4}$ & & & & & & & & & & & & & & $/$ & 4 & -3 & 5 \\
\hline $\mathbf{1 5}$ & & & & & & & & & & & & & & & $/$ & -4 & 3 \\
\hline $\mathbf{1 6}$ & & & & & & & & & & & & & & & & $/$ & -1 \\
\hline
\end{tabular}

Table 2. Coefficients of correlation between the activities (for the presented case)

\subsection{Discussion}

When checking, if there are some interrelationships between the activities, we have to discuss these combinations, based on the results in Table 2 (for values lower than -6 or higher than 6 ):

- Assembly the parts : Absence from company - of course: more productive work, less absence and loses (and vice versa).

- Assembly the parts : Private absence from workplace - the same comment as above.

- Depositing the parts : Work on other workplace - the same comment as above.

- Annotation of work results : Cleaning the machine - normal sequence after the job's completion.

- Annotation of work results : Keeping workplace in order - after the job's completion some maintenance is normally needed.

- Annotation of work results : Conversation about tasks - it is evident that before starting new task some instructions from foreman are usually needed; maybe some improvements in working documentation are required (useful comment no. 1).

- Cleaning the machine : Keeping workplace in order - this activities are connected; no changes.

- Cleaning the machine : Conversation about tasks - maybe the information about the machine maintenance is insufficient or working documentation is incomplete (useful comment no. 2).

- Keeping workplace in order : Conversation about tasks - the same comment as above.

- Machine failure : Private conversation - during the machine downtime the worker spends time in private chatting; time to repair should be as short as possible; maybe we should hire more maintenance staff or improve knowledge of the existent service technicians to be faster (useful comment no. 3).

- Business meeting : Private absence from workplace - obviously the workers take the opportunity of absence; when they are outside the workshop hall it is possible to return later than adequately; maybe we should change the room for business meetings, selecting closer places or some corner in the workshop directly (useful comment no. 4).

It is evident that with the correlation test we are getting an additional tool for work sampling results evaluation. In our simple case we have 4 comments, which are giving the basis for further investigation. Even in simpler cases some hints for critical reflection are present. Sometimes they are correct (activities' interrelationship exists) and require some changes in the production process, but it may also happen that they will be useless.

\section{Conclusion}

Work sampling is the statistical technique for determining the proportion of time spent by workers in various defined categories of activity. Workers are observed at random times throughout the work period, recording what they are doing each time. Work sampling permits quick analysis, recognition, and enhancement of job responsibilities, tasks, performance competencies, and organizational work flows. Its primary advantage is in studying nonrepetitive activities, but it can also be used to develop time standards for repetitive jobs. In such cases a lot of observations (1000 and more) are required to achieve acceptable accuracy. 
In the paper we introduce the pairwise correlation comparison of the measured hourly proportions of all activities to check, if there are some interrelationships. The results of the work sampling method are given in tables (hard to read, pure statistics), now some additional calculations are made to enable the discussion between the members of the work design team about the necessary process improvements. With the correlation analysis we are getting the first signal that some activities trigger the occurrence of another (maybe non-value-adding) activity. This is the essential contribution in the decision making process.

The implementation of correlation analysis is of immense benefit to managers in enhancing companies work performance and productivity. This paper contributes both theoretically (new idea) and empirically (test case) to the finding on labour productivity. Future research should include more sophisticated statistical methods.

\section{Acknowledgement}

The authors acknowledge the financial support from the Slovenian Research Agency (research core funding No. P20190). Thanks also to the researchers in the textile company giving us the work sampling data.

\section{References}

[1] Hajikazemi, S.; Andersen, B. \& Langlo, J. A. (2017). Analyzing electrical installation labor productivity through work sampling, International Journal of Productivity and Performance Management, Vol. 66, No. 4, pp. 539-553, ISSN 1741-0401, DOI:10.1108/IJPPM-06-2016-0122

[2] Saric, T.; Simunovic, G.; Simunovic, K. \& Svalina, I. (2016). Estimation of machining time for CNC manufacturing using neural computing, International Journal of Simulation Modelling, Vol. 15, No. 4, pp. 663-675, ISSN 17264529, DOI:10.2507/IJSIMM15(4)7.359

[3] Geng, H. (Ed.) (2004). Manufacturing Engineering Handbook, McGraw-Hill, ISBN 978-0071398251, New York

[4] Antinaho, T.; Kivinen, T.; Hurunen, H. \& Partanen, P. (2015). Nurses' working time use - how value adding it is?, Journal of Nursing Management, Vol. 23, No. 8, pp. 1094-1105, ISSN 0966-0429, DOI:10.1111/jonm.12258

[5] Stanisavljev, S.; Cockalo, D.; Klarin, M.; Brkic, V. S. \& Dordevic, D. (2015). Stohastic model to determine the elements of the production cycle time: case of Serbian textile industry, Fibres \& Textiles in Eastern Europe, Vol. 23, No. 5, pp. 23-29, ISSN 1230-3666, DOI:10.5604/12303666.1161752

[6] Tahriri, F.; Mousavi, M.; Yap, H. J.; Siti Zawiah, M. D. \& Taha, Z. (2015). Optimizing the robot arm movement time using virtual reality robotic teaching system, International Journal of Simulation Modelling, Vol. 14, No. 1, pp. 28-38, ISSN 1726-4529, DOI:10.2507/IJSIMM14(1)3.273

[7] Haskovic, D.; Katalinic, B.; Zec, I.; Kukushkin, I. \& Zavrazhina, A. (2016). Structure and working modes of the intelligent adviser module, Proceedings of the $27^{\text {th }}$ DAAAM International Symposium, pp.0866-0875, B. Katalinic (Ed.), DAAAM International Vienna, ISBN 978-3-902734-08-2, ISSN 1726-9679, Vienna

[8] Car, M. \& Adzam, A. (2009). Influence of the technological process structure elements model on approaches of time standards determining, Proceedings of the $13^{\text {th }}$ International Research/Expert Conference TMT 2009, pp. 197-200, Hammamet, Tunisia

[9] Unal, C. (2013). A new line balancing algorithm for manufacturing cell transformation in apparel industry, Industria Textila, Vol. 64, No. 3, pp. 155-162, ISSN 1222-5347

[10] Roche, M. A.; Friedman, S.; Duffield, C.; Twigg, D. E. \& Cook, R. (2017). A comparison of nursing tasks undertaken by regulated nurses and nursing support workers: a work sampling study, Journal of Advanced Nursing, Vol. 73, No. 6, pp. 1421-1432, ISSN 0309-2402, DOI:10.1111/jan.13224

[11] Trask, C.; Teschke, K.; Morrison, J.; Village, J.; Johnson, P. \& Koehoorn, M. (2010). Using observation and selfreport to predict mean, $90^{\text {th }}$ percentile, and cumulative low back muscle activity in heavy industry workers, The Annals of Occupational Hygiene, Vol. 54, No. 5, pp. 595-606, ISSN 0003-4878, DOI:10.1093/annhyg/meq011

[12] Pinosova, M.; Andrejiova, M.; Kralikova, R.; Hricova, B.; Lumnitzer, E. \& Wessely, E. (2015). Assessment of hearing impairment risk from the point of view of long-term exposure to noise in working environment, Chapter 30 in DAAAM International Scientific Book 2015, pp. 345-358, B. Katalinic (Ed.), DAAAM International Vienna, ISBN 978-3-902734-05-1, ISSN 1726-9687, Vienna

[13] Robinson, M. A. (2012). How design engineers spend their time: job content and task satisfaction, Design Studies, Vol. 33, No. 4, pp. 391-425, ISSN 0142-694X, DOI:10.1016/j.destud.2012.03.002

[14] Stevenson, W. J. (1993). Production / Operations Management, $4^{\text {th }}$ edition, Irwin, ISBN 0-256-10511-1, Homewood

[15] Robinson, M. A. (2010). Work sampling: methodological advances and new applications, Human Factors and Ergonomics in Manufacturing \& Service Industries, Vol. 20, No. 1, pp. 42-60, ISSN 1090-8471, DOI: $10.1002 / \mathrm{hfm} .20186$

[16] Gouett, M. C.; Haas, C. T.; Goodrum, P. M. \& Caldas, C. H. (2011). Activity analysis for direct-work rate improvement in construction, Journal of Construction Engineering and Management - ASCE, Vol. 137, No. 12, pp. 1117-1124, ISSN 0733-9364, DOI:10.1061/(ASCE)CO.1943-7862.0000375 